\title{
Erratum to: Haploid plants from anther cultures of poplar (Populus $\times$ beijingensis)
}

\author{
Ying Li $\cdot$ Hao Li $\cdot$ Zhong Chen $\cdot$ Le-Xiang Ji • \\ Mei-Xia Ye $\cdot$ Jia Wang $\cdot$ Lina Wang $\cdot$ \\ Xin-Min An
}

Published online: 4 December 2013

(C) Springer Science+Business Media Dordrecht 2013

\section{Erratum to: Plant Cell Tiss Organ Cult (2013) \\ 114:39-48 \\ DOI 10.1007/s11240-013-0303-5}

There is an error in the caption to Fig. 2 in the original publication. The text for figure part $2 \mathrm{a}$ actually concerns part $2 \mathrm{~b}$ and vice versa. The correct caption is shown below.
Fig. 2 Plant regeneration from another culture of poplar $(P . \times$ beijingensis $)$. a Haploid plantlets on rooting medium after 1-month culture. b Diploid plantlets after 2 months of culture in rooting medium. c Triploid plantlet after 2 months of culture in rooting medium. Bars $=1 \mathrm{~cm}$

The online version of the original article can be found under doi:10. 1007/s11240-013-0303-5.

Y. Li · H. Li · Z. Chen - L.-X. Ji · M.-X. Ye - J. Wang

L. Wang $\cdot$ X.-M. An $(\bowtie)$

National Engineering Laboratory for Tree Breeding (NDRC),

Key Laboratory of Genetics and Breeding in Forest Trees and Ornamental Plants of Ministry of Education (MOE), Tree and Ornamental Plant Breeding and Biotechnology Laboratory of State Forestry Administration (SFA), Beijing Forestry University, Beijing 100083, People's Republic of China e-mail: anxinmin@bjfu.edu.cn 